\title{
Transarterial chemo-embolisation of hepatocellular carcinoma: impact of liver function and vascular invasion
}

Imam Waked ${ }^{1}$, Sarah Berhane ${ }^{2}$, Hidenori Toyoda ${ }^{3}$, Stephen L Chan ${ }^{4}$, Nicholas Stern ${ }^{5}$, Daniel Palmer ${ }^{2}$, Toshifumi Tada ${ }^{3}$, Winnie Yeo ${ }^{6}$, Frankie Mo ${ }^{6}$, Dominik Bettinger ${ }^{7}$, Martha M Kirstein ${ }^{8}$, Mercedes Iñarrairaegui ${ }^{9}$, Asmaa Gomaa ${ }^{1}$, Arndt Vogel ${ }^{8}$, Tim Meyer ${ }^{10}$, Bruno Sangro ${ }^{9}$, Paul Lai ${ }^{11}$, Takashi Kumada ${ }^{3}$ and Philip J Johnson*,2,12

${ }^{1}$ Department of Hepatology, National Liver Institute, Menoufeya University, Menoufia Governorate, Egypt; ${ }^{2}$ Department of Molecular and Clinical Cancer Medicine, University of Liverpool, The Sherrington Building, Ashton Street, Liverpool L69 3GA, UK; ${ }^{3}$ Department of Gastroenterology and Hepatology, Ogaki Municipal Hospital, 4-86 Minaminokawa-cho, Ogaki, Gifu 503-8052, Japan; ${ }^{4}$ Department of Anatomical \& Cellular Pathology, Chinese University of Hong Kong, Hong Kong Cancer Institute, Hong Kong, China; ${ }^{5}$ Digestive Diseases Unit, Aintree University Hospitals NHS Foundation Trust, University Hospital Aintree, Liverpool, UK; ${ }^{6}$ State Key Laboratory in Oncology in South China, Sir Y. K. Pao Centre for Cancer, Department of Clinical Oncology, Chinese University of Hong Kong, Hong Kong Cancer Institute, Hong Kong, China; ${ }^{7}$ Department of Internal Medicine II, University Hospital Freiburg, Hugstetter Street 55, Freiburg D-79106, Germany; ${ }^{8}$ Department of Gastroenterology, Hepatology and Endocrinology, Medical School Hannover, Carl Neuberg Street 1, Hannover 30625, Germany; ${ }^{~}$ Liver Unit and HPB Oncology Area, Clinica Universidad de Navarra; and Centro de Investigacion Biomedica en Red de Enfermedades Hepaticas y Digestivas (CIBEREHD), Pamplona, Spain; ${ }^{10}$ Department of Oncology, UCL Cancer Institute, University College London, London, UK; ${ }^{11}$ Department of Surgery, Prince of Wales Hospital, Chinese University of Hong Kong, Hong Kong, China and ${ }^{12}$ The Clatterbridge Cancer Centre NHS Foundation Trust, Clatterbridge Road, Bebington, Wirral CH63 4JY, UK

Background: Transarterial chemo-embolisation (TACE) is recommended for patients with BCLC intermediate stage hepatocellular carcinoma (stage B), particularly in patients with good underlying liver function and minimal symptoms. The hepatoma arterial embolisation prognostic (HAP) score combines measures of liver function and tumour-related factors to offer a simple prognostic scoring system. The Albumin-Bilirubin (ALBI) grade permits assessment of the impact of liver function on survival. We aimed to investigate these two models and vascular invasion (VI).

Methods: In an international cohort of 3030 patients undergoing TACE, we examined the impact of liver function as assessed by the ALBI score, the HAP score and VI on survival.

Results: Classification according to ALBI grade resulted in non-overlapping survival curves in the overall data set and all regional cohorts. The HAP score was also validated. Tumour number, aetiology and VI were identified as additional independent prognostic risk factors not currently included in the HAP score. Survival was particularly poor for patients with VI.

Conclusions: The ALBI grade categorised patients receiving TACE into three clear prognostic groups, thereby emphasising the importance of underlying liver function in the outcome of TACE. The HAP score has been validated internationally and the serious adverse impact of $\mathrm{VI}$ is clearly shown.

*Correspondence: Professor PJ Johnson; E-mail: Philip.Johnson@liverpool.ac.uk 
International guidelines recommend Transarterial chemo-embolisation (TACE) for patients with hepatocellular carcinoma (HCC) at the BCLC intermediate stage (B) or for those patients in the early stage that are not candidates for percutaneous ablation, liver resection or transplantation (Bruix and Sherman, 2011). This recommendation was based upon two randomised trials and a subsequent systematic review (Llovet et al, 2002; Lo et al, 2002; Llovet and Bruix, 2003). However, the benefits from TACE remain controversial (Marelli et al, 2007; Curley et al, 2012; Meyer et al, 2013). A recent Cochrane review concluded that there was no firm evidence to support or refute the benefit of TACE for patients with unresectable HCC (Oliveri et al, 2011), although this conclusion has, itself, been robustly challenged (Forner et al, 2012).

Nonetheless, there is little argument that the degree of underlying liver (dys)function is an important factor determining survival and hence in defining the patient groups most likely to benefit from this form of treatment. International guidelines suggest that TACE should be confined to those with Child-Pugh (C-P) 'A' disease and that patients with vascular invasion (VI) should receive sorafenib rather than TACE although VI was not excluded in one of the original RCTs (Lo et al, 2002). However, it is now well-established that TACE can be performed safely in the presence of some degree of VI and, in current clinical practice, a significant proportion of patients undergoing TACE do, in fact, have VI. We have previously developed and validated a simple model, the hepatoma arterial embolisation prognostic (HAP) score (Kadalayil et al, 2013), based on a cohort of UK patients, that permits assessment of prognosis after TACE. The model was built on the clinical parameters of bilirubin, albumin, tumour size and Albumin-Bilirubin (AFP), the former two presumably reflecting the impact of liver function and the latter two, the impact of tumour-related factors, on survival.

We have now assembled a comprehensive global data set that includes patient level data from $>3000$ patients undergoing TACE and undertaken a rigorous statistical analysis of the factors influencing survival. We placed particular emphasis on underlying liver function and the presence or absence of VI and, in the process thereof, we sought to validate the HAP score. Liver function was assessed by applying the recently developed ALBI score (Johnson et al, 2014), a simple objective and extensively validated (Chan et al, 2015; Hiraoka et al, 2015; Chan et al, 2016), approach.

\section{PATIENTS AND METHODS}

The cohorts comprised patients undergoing TACE in four different regions namely Europe, Japan, China (Hong Kong) and Egypt (Table 1). The European cohort comprised 413 patients from the UK (Birmingham, Liverpool and London), 731 from Germany (Hannover and Freiburg) and 88 patients from Pamplona, Spain. Some of the data from the UK (London) came from those on which the HAP score was originally derived. These patients were excluded for the HAP score validation. The Japanese cohort $(n=655)$ were recruited from five institutions in the Western part of Japan, as previously reported by Toyoda et al (2006). The Chinese patients $(n=145)$ were from those attending the Joint Hepatoma Clinic at the Prince of Wales Hospital, Hong Kong and the Egyptian cohort $(n=998)$ were from those referred to the Oncology department of the National Liver Institute in Shebeen ElKom, Egypt. Detailed demographic data is given in Table 1. Data recorded in each cohort include age, gender, albumin $\left(\mathrm{gl}^{-1}\right)$, bilirubin $\left(\mu \mathrm{moll}{ }^{-1}\right)$, tumour number (solitary or multiple), tumour size $(\mathrm{cm})$, VI, AFP $\left(\mathrm{ng} \mathrm{ml}^{-1}\right)$, C-P grade and aetiology (HCV, HBV or 'other'). 'Other' comprised mainly patients with alcoholic liver disease. Laboratory data were recorded within the 6 week period before the first TACE procedure which was, in turn, undertaken within 6 weeks of diagnosis. Vascular invasion (including portal vein, hepatic vein and inferior vena cava involvement) was assessed in the portal phase of computed

\begin{tabular}{|c|c|c|c|c|c|}
\hline Variables & Europe $(n=1232)$ & Japan $(n=655)$ & Egypt $(n=998)$ & Hong Kong $(n=145)$ & All $(n=3030)$ \\
\hline$\%$ Male & $83.12, n=1232$ & $74.66, n=655$ & $83.27, n=998$ & $85.52, n=145$ & $81.45, n=2769$ \\
\hline Age (median, IQR) & $\begin{array}{c}66.48(59.00-73.18) \\
n=1230\end{array}$ & $\begin{array}{c}65.00(58.00-73.00) \\
n=655\end{array}$ & $\begin{array}{c}57.00(51.00-62.00), \\
n=998\end{array}$ & $\begin{array}{c}65.00(56.00-71.00) \\
n=145\end{array}$ & $\begin{array}{c}62.77(55.00-70.07) \\
n=3028\end{array}$ \\
\hline Albumin, $\mathrm{gl}^{-1}$ (median, IQR) & $\begin{array}{c}37.00(33.00-41.00), \\
n=1214\end{array}$ & $\begin{array}{c}32.00(28.00-36.00) \\
n=653\end{array}$ & $\begin{array}{c}33.00(29.00-37.00) \\
n=998\end{array}$ & $\begin{array}{c}35.00(32.00-39.00) \\
n=145\end{array}$ & $\begin{array}{c}35.00(30.00-39.00) \\
n=3010\end{array}$ \\
\hline Bilirubin, $\mathrm{mmol}^{-1}$ (median, IQR) & $\begin{array}{c}16.00(10.94-26.00), \\
n=1213\end{array}$ & 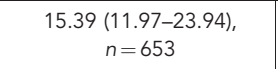 & $\begin{array}{c}22.23(13.68-32.49), \\
n=998\end{array}$ & $14.00(9.00-22.00), n=145$ & $\begin{array}{c}17.10(11.97-27.36), \\
n=3009\end{array}$ \\
\hline Tumour size, cm (median, IQR) & $5.00(3.40-7.60), n=1180$ & $3.50(2.20-5.40), n=594$ & $6.00(4.00-8.00), n=998$ & $6.00(3.80-10.00), n=141$ & $5.00(3.40-7.60), n=2913$ \\
\hline$\%$ Multifocal & $66.24, n=1161$ & $69.27, n=654$ & $75.75, n=998$ & $58.33, n=144$ & $69.73, n=2957$ \\
\hline AFP, $\mathrm{ng} \mathrm{ml}^{-1}$ (median, IQR) & $\begin{array}{c}46.00(6.70-534.50), \\
n=1045\end{array}$ & $\begin{array}{c}45.45(12.40-510.00), \\
n=614\end{array}$ & $\begin{array}{c}129.00(17.00-600.00) \\
n=998\end{array}$ & $\begin{array}{c}92.00(10.00-1365.00) \\
n=145\end{array}$ & $\begin{array}{c}70.45(11.00-584.00) \\
n=2802\end{array}$ \\
\hline INR (median, IQR) & $1.10(1.01-1.20), n=851$ & NA & $1.40(1.20-1.70), n=998$ & $1.14(1.07-1.22), n=145$ & $1.20(1.10-1.40), n=1994$ \\
\hline ALBI score (median, IQR) & $\begin{array}{c}-2.34(-2.72 \text { to }-1.91), \\
n=1203\end{array}$ & $\begin{array}{c}-1.97(-2.36 \text { to }-1.55) \\
n=653\end{array}$ & $\begin{array}{c}-1.91(-2.34 \text { to }-1.55) \\
n=998\end{array}$ & $\begin{array}{c}-2.29(-2.59 \text { to }-1.90) \\
n=145\end{array}$ & $\begin{array}{c}-2.10(-2.53 \text { to }-1.67) \\
n=2999\end{array}$ \\
\hline$\%$ ALBI grade $(1: 2: 3)$ & $32.09: 60.93: 6.98, n=1203$ & $\begin{array}{c}13.02: 70.75: 16.23 \\
n=653\end{array}$ & $\begin{array}{c}15.63: 69.14: 15.23 \\
n=998\end{array}$ & $24.83: 67.59: 7.59, n=145$ & $\begin{array}{c}22.11: 66.12: 11.77 \\
n=2999\end{array}$ \\
\hline$\%$ Child-Pugh (A: B:C) & $73.94: 24.62: 1.45, n=1174$ & $52.06: 41.22: 6.72, n=655$ & $\begin{array}{c}47.60: 46.89: 5.51 \\
\quad n=998\end{array}$ & $77.24: 21.38: 1.38, n=145$ & $\begin{array}{c}60.43: 35.60: 3.97 \\
n=2972\end{array}$ \\
\hline \% HAP class (A: B: C: D) & $\begin{array}{c}18.72: 34.42: 31.95: 14.91 \\
n=892 \text { (Liverpool, } \\
\text { Birmingham, Germany and } \\
\text { Spain only) }\end{array}$ & $\begin{array}{c}13.49: 32.40: 38.53: 15.59 \\
n=571\end{array}$ & $\begin{array}{c}9.02: 22.55: 41.08: 27.35 \\
n=998\end{array}$ & $\begin{array}{c}12.06: 37.59: 29.79: 20.57 \\
n=141\end{array}$ & $\begin{array}{c}13.49: 29.59: 36.78: 20.14 \\
n=2602\end{array}$ \\
\hline$\%$ Vascular invasion & $10.61, n=1225$ & $30.28, n=654$ & $10.32, n=998$ & $11.03, n=145$ & $14.79, n=3022$ \\
\hline \% HCV: HBV: other & $\begin{array}{c}24.29: 12.19: 63.52 \\
\quad n=1165\end{array}$ & $\begin{array}{c}56.66: 18.42: 24.92 \\
n=646\end{array}$ & $98.39: 1.10: 0.50, n=996$ & $8.33: 79.86: 11.81, n=144$ & $\begin{array}{c}55.61: 13.11: 31.28 \\
n=2951\end{array}$ \\
\hline Overall survival (months, $95 \% \mathrm{Cl}$ ) & $16.6(15.4-18.0), n=1226$ & $22.3(20-24.5), n=655$ & $18.0(17.0-19.0), n=998$ & $19.9(14.2-25.6), n=143$ & $18.6(17.9-19.5), n=3022$ \\
\hline
\end{tabular}


tomography and, supplemented where appropriate, by arterial portography. Assessments were made within the 6 week period before treatment. In the Japanese cohort detailed information concerning the extent of portal vein invasion, ranging from VP0 to VP4 was recorded. VP0 indicated no tumour thrombus in the portal vein; VP1, tumour thrombus distal to, but not involving, the second-order branches; VP2, tumour thrombus in the second-order branches; VP3, tumour thrombus in the first-order branches; and VP4, tumour thrombus in the main trunk (Katagiri and Yamamoto, 2014; Kudo et al, 2015). For the purposes of the present analysis, VP2 and VP3 were combined.

The centres involved had extensive experience in the management of HCC and the use of TACE. We included all patients that were classified by the local investigator as undergoing TACE as their primary treatment, excluding only those where TACE was used as a bridge to transplantation or other potentially curative treatment options. Neither the response, nor any specific aspects of the procedure such as type of cytotoxic drug or embolic agent used or frequency of repeat TACE, or other treatment after the primary treatment, were recorded for the purpose of this study. All data were analysed in the UK (University of Liverpool) and used exactly as presented by the contributing investigator. Liver function was assessed by the C-P grade (as graded by the local investigator) and the ALBI score, the latter being graded according to the published cutoff points. Grades 1, 2 and 3 refer to good, intermediate and poor liver function, respectively.

Statistical methods. All statistical analyses were undertaken using Stata/SE 14.1 (StataCorp LLC, Lakeway Drive, TX, USA). The HAP score (Kadalayil et al, 2013) and ALBI grade (Johnson et al, 2014) were calculated as previously described. Survival (in months) was calculated from date of TACE treatment until date of death or date of last follow-up. Survival according to HAP score or ALBI grade was plotted using the Kaplan-Meier method. The different classification systems were compared using the Harrell's C (a measure of predictive power; Harrell et al, 1982; Harrell et al, 1996; Newson, 2010) and Akaike information criterion (AIC; a measure

\section{Table 2. Univariable Cox regression}

\begin{tabular}{|c|c|c|c|}
\hline Variable & $\begin{array}{c}\text { Hazard ratio } \\
(95 \% \mathrm{Cl})\end{array}$ & $P$-value & $\begin{array}{l}\text { LR test of } \\
\text { theta }=0\end{array}$ \\
\hline $\begin{array}{l}\text { Age groups } \\
\text { Under } 51 \\
51-60 \\
61-70 \\
\text { Over } 70\end{array}$ & $\begin{array}{c}1 \\
0.967(0.822-1.138) \\
0.914(0.779-1.072) \\
0.950(0.805-1.122)\end{array}$ & $\begin{array}{l}0.688 \\
0.269 \\
0.546\end{array}$ & 0.003 \\
\hline $\begin{array}{l}\text { Gender } \\
\text { Female } \\
\text { Male }\end{array}$ & $\begin{array}{c}1 \\
1.099(0.980-1.234)\end{array}$ & 0.108 & 0.005 \\
\hline Albumin $\left(\left.g\right|^{-1}\right)$ & $0.958(0.951-0.966)$ & $<0.0001$ & $<0.0001$ \\
\hline Log 10 bilirubin & $1.894(1.608-2.231)$ & $<0.0001$ & 0.007 \\
\hline $\begin{array}{l}\text { Tumour number } \\
\text { Solitary } \\
\text { Multiple }\end{array}$ & $\begin{array}{c}1 \\
1.279(1.158-1.412)\end{array}$ & $<0.0001$ & 0.005 \\
\hline Tumour size $(\mathrm{cm})$ & $1.072(1.059-1.086)$ & $<0.0001$ & 0.084 \\
\hline $\begin{array}{l}\text { Vascular invasion } \\
\text { No } \\
\text { Yes }\end{array}$ & $\begin{array}{c}1 \\
2.282(2.024-2.573)\end{array}$ & $<0.0001$ & $<0.0001$ \\
\hline Log 10 AFP & $1.263(1.215-1.312)$ & $<0.0001$ & $<0.0001$ \\
\hline $\begin{array}{l}\text { Aetiology } \\
\text { HCV } \\
\text { HBV } \\
\text { Other }\end{array}$ & $\begin{array}{c}1 \\
1.211(1.055-1.391) \\
1.276(1.138-1.432)\end{array}$ & $\begin{array}{c}0.007 \\
<0.0001\end{array}$ & 0.077 \\
\hline
\end{tabular}

of model fit; Akaike, 1998). Higher values of the former and lower values of the latter indicates a better prognostic utility of the model. Log-rank tests were used to compare between the survival curves within each staging group. Alphafetoprotein (AFP) and bilirubin were log-transformed due to extreme skewness. Variables that influence survival were identified using univariable Cox proportional hazards model. Using forward selection of variables at the $P=0.05$ level (and likelihood ratio test at each step), a multivariable Cox proportional hazards model was built to explain survival in TACE patients. For the Cox regression models, all the cohorts were merged and 'region' was used as a frailty term. The proportional hazards assumption was tested on the basis of scaled Schoenfeld residuals after fitting the Cox regression model. For all tests, statistical significance level was set at $5 \%$.

\section{RESULTS}

The results from the univariable Cox regression analysis (Table 2) showed that albumin, bilirubin, tumour number, tumour size, VI and aetiology were prognostic in patients undergoing TACE (all $P \leqslant 0.0001$ ). The multivariable Cox regression model (Table 3) showed that the key variables influencing survival were related to tumour characteristics (tumour size, tumour number, AFP and VI; $P<0.0001)$, liver function (albumin and bilirubin) $(P<0.0001)$, aetiology $(P=0.0082)$ and age $(P=0.0012$; Table 3$)$. Effect of age on survival was more notable in those over 70 years of age compared with the other age groups (Table 3; Supplementary Table 1). Most patients had CP grade 'A' liver function; the remainder had CP grade $B$ with only a small percentage (4\%) having $\mathrm{CP}$ grade $\mathrm{C}$ (Table 1). Assessing liver function by the two variables of bilirubin and albumin as defined in the ALBI score revealed a clear discrimination in survival between each ALBI grade in all separate regions (Figures 1A-D) and overall (Figure 2A). The model also revealed clear separation within $\mathrm{C}-\mathrm{P}$ 'A' patients (Figure 2B; Supplementary Figures 1a-d). Assessing liver function with the C-P score also showed separation by grade in each individual region (Supplementary Figures 2a-d). There was no clear difference between C-P B and C-P C particularly amongst the European, Japanese and Hong Kong cohorts but, as

\begin{tabular}{|l|c|c|}
\hline \multicolumn{3}{|l|}{ Table 3. Multivariable Cox regression } \\
\hline Variable & Hazard ratio (95\% Cl) & $P$-value \\
\hline $\begin{array}{l}\text { Vascular invasion } \\
\text { No } \\
\text { Yes }\end{array}$ & 1 & \\
\hline Albumin $\left(\mathrm{gl}^{-1}\right)$ & $1.751(1.515-2.025)$ & $<0.0001$ \\
\hline Log10 AFP & $0.959(0.950-0.968)$ & $<0.0001$ \\
\hline Tumour size (cm) & $1.209(1.158-1.261)$ & $<0.0001$ \\
\hline Log10 bilirubin & $1.054(1.038-1.070)$ & $<0.0001$ \\
\hline Tumour number & $1.697(1.394-2.066)$ & $<0.0001$ \\
$\quad$ Solitary & 1 & \\
Multiple & $1.284(1.151-1.432)$ & $<0.0001$ \\
\hline Age groups & 1 & \\
Under 51 & $0.946(0.793-1.130)$ & 0.541 \\
51-60 & $0.943(0.791-1.123)$ & 0.508 \\
61-70 & $1.209(1.000-1.463)$ & 0.05 \\
Over 70 & 1 & \\
\hline Aetiology & $1.233(1.050-1.449)$ & 0.011 \\
HCV & $1.231(1.076-1.408)$ & 0.002 \\
HBV &
\end{tabular}

Abbreviations: $\mathrm{AFP}=$ alphafetoprotein; $\mathrm{Cl}=$ confidence interval; $\mathrm{HCV}=$ hepatitis $\mathrm{C}$ virus; $\mathrm{HBV}=$ hepatitis $\mathrm{B}$ virus. Theta $=0.0185, \mathrm{LR}$ test of theta $=0$, chibar2(01) $=17.83, P<0.0001$. 

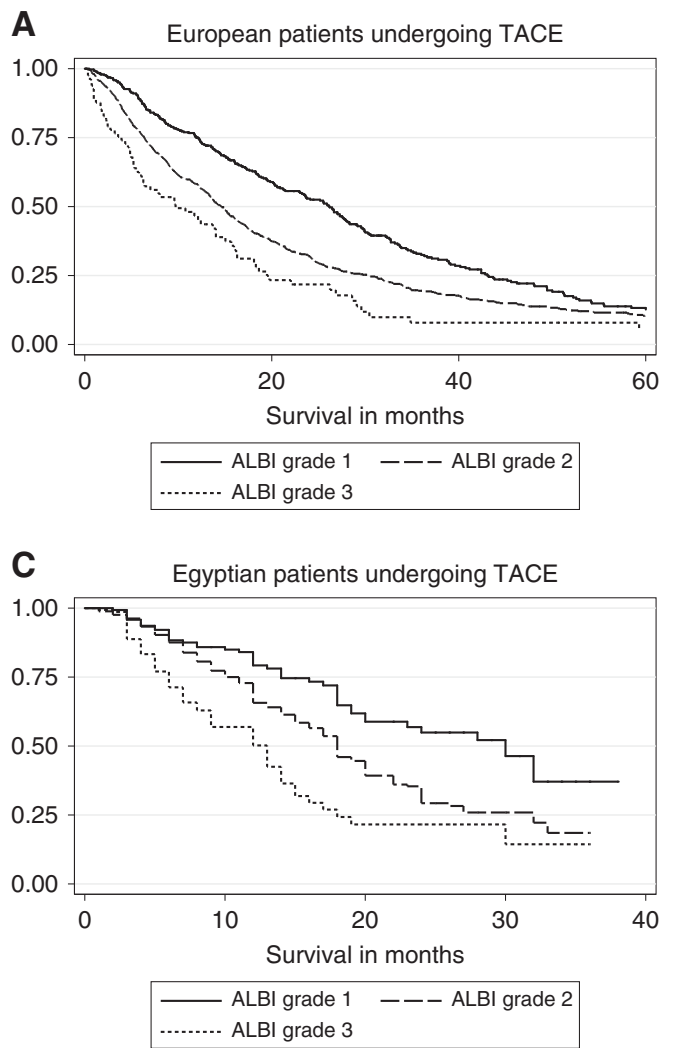

B

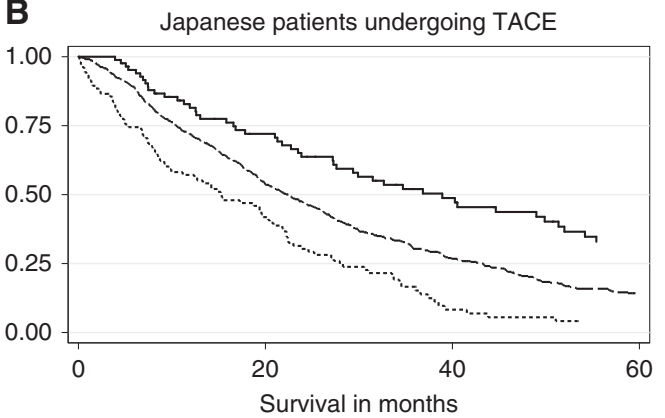

- ALBI grade 1 - - ALBI grade 2

......... ALBI grade 3

D Hong Kong (China) patients undergoing TACE

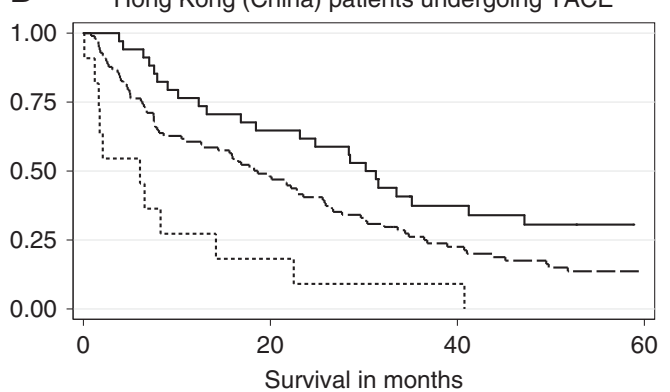

Survival in months

Figure 1. Kaplan-Meier curves depicting survival according to ALBI grade. Patients are classified as undergoing TACE from (A) Europe, (B) Japan, (C) Egypt and (D) Hong Kong, China.

expected, the numbers in the C-P C group were low. Results after merging the data sets from all four regions showed clear separation between the three C-P grades (Figure 2C). Both by visual inspection and formal statistical analysis (via Harrell's C statistic), the ALBI score is at least as effective as C-P in discriminating between prognostic groups. Harrell's C statistic was 0.5661 and 0.5586 for ALBI and C-P, respectively. The corresponding AIC values were 26963.33 and 26548.21 , respectively.

The HAP score was originally developed using the UK data sets only (London). Applying the HAP score to each of the other cohorts - Europe (Liverpool, Birmingham, Spain and Germany), Japan, Egypt and Hong Kong - produced four prognostic groups in each region (Supplementary Figures 3a-d) and overall (Figure 2D), thereby extending the generalisability of the score, although it should be noted that there was considerable overlap between HAP 2 and 3 in the Egyptian (Supplementary Figure 3c), and to a lesser extent the Hong Kong cohorts (Supplementary Figure 3d). Merging all the cohorts, however, generated four clear prognotic groups (log-rank tests, $P<0.0001$ for all combinations; Figure 2D).

Overall $15 \%$ of patients had VI and there was a very clear difference in survival according to presence or absence thereof, in all regions (Supplementary Figures $4 \mathrm{a}-\mathrm{d}$ ) and overall (Figure 2E). Among those with VI survival was particularly poor, ranging from 2.7-10.7 months in the various regions and 8.2 months overall (Supplementary Figures 4a-d; Figure 2E). In the Japanese cohort, there was clear deterioration in overall survival with increasing extent of the portal vein involvement (Figure $2 \mathrm{~F}$ ).

Median survival (and 95\% CI) for each of the above sub-groups, as well as the Harrell's C and AIC scores are summarised in Table 4 and Supplementary Table 2. Log-rank test outcomes for each combination of the survival curves in all the figures is summarised in Supplementary Table 3.

\section{DISCUSSION}

Our multivariable analysis showed that the key variables influencing survival were related to tumour characteristics (tumour size, tumour number, AFP and VI), liver function (albumin and bilirubin) and aetiology. These results were largely in agreement with the literature (Savastano et al, 1999; Lladó et al, 2000; O'Suilleabhain et al, 2003; Grieco et al, 2005; Takayasu et al, 2006) and our previous analysis (based largely on the current UK data set). In the latter, we used bilirubin, albumin, tumour size and AFP to develop a score (the HAP score) that gave accurate and nationally validated prognostication (Kadalayil et al, 2013). The present study lends international support to the HAP score, but as noted above there is considerable overlap between HAP stages $\mathrm{B}$ and $\mathrm{C}$ in the Chinese and Egyptian cohorts.

However, the data set on which the HAP score was originally developed did not contain information on tumour number and the number of patients with different aetiologies and VI was too small for meaningful statistical analysis; these parameters did not, therefore, enter the model. Thus, it became apparent in the present, much larger and international data set, that VI, tumour number, age and aetiology were also important, and these factors could be added to the HAP score to increase its prognostic utility. It would be possible to build a more rigorous model involving these variables, but the inevitable increase in complexity would detract from relative simplicity and ready clinical applicability of the currently formulated HAP score. Our data sets were accrued before the recent publication of other scoring systems designed to facilitate identification of patients appropriate for TACE and we have not therefore collected the variables that would be required for comparison with HAP (Hucke et al, 2014; Adhoute et al, 2015). 

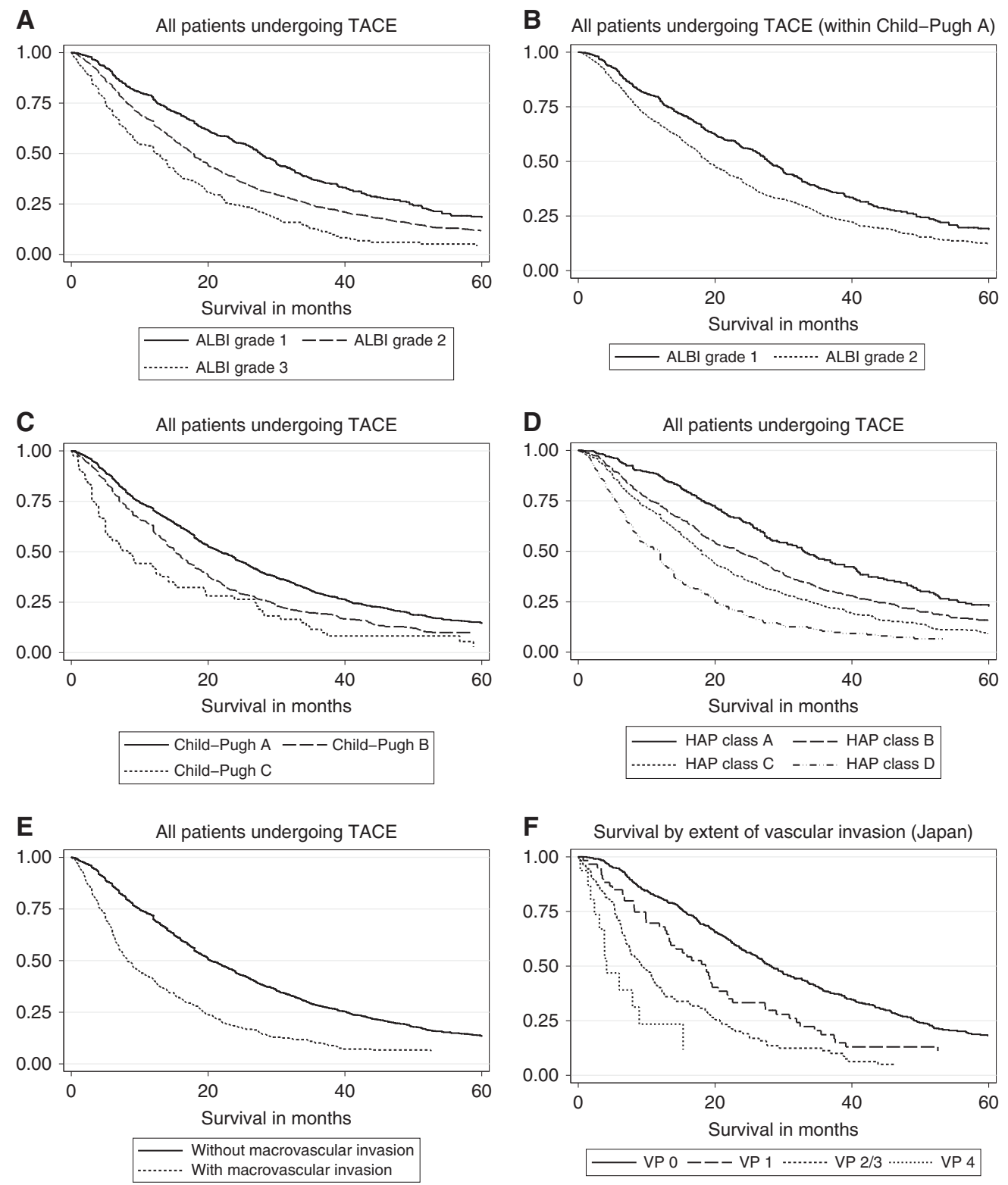

Figure 2. Kaplan-Meier curves depicting survival in all the patients undergoing TACE. Patients are classified according to (A) ALBI grade, (B) ALBI grade within C-P grade A, (C) C-P grade, (D) HAP class, (E) the presence or absence of macrovascular invasion and (F) the extent of vascular invasion (Japan).

Our results also give particular insight into two of the key prognostic variables that are integral to the model namely liver function and VI. Thus albumin and bilirubin are clear measures of liver (dys) function and form the basis of our ALBI score. In all regions there is clear discrimination in survival according to ALBI and this was also maintained within patients classified as C-P ' $\mathrm{A}$ '. Despite this clear discrimination within regional groups, the percentage falling into each ALBI group and the survival within each group was different. This presumably reflects the different availability of, and indication for, various therapeutic options and treatment algorithms in the different regions and the different aetiologies. For example, Sorafenib was not available in Egypt and liver transplantation was not available in the Japanese or Hong Kong cohorts. It should be noted here that the ALBI score is not an HCC staging system since it only measures liver function, taking no account of tumour-related factors. To this extent it is not directly comparable to the HAP score which was derived to assess survival after arterial therapies by combining both liver function and tumour-related factors.

Our current analysis suggests that the ALBI score is at least as discriminatory, in prognostic terms, as the CPS in the TACE setting and in a recent study on a similar population, but including those undergoing radio-embolisation, Hickey et al (2016) concluded that the ALBI score 'outperformed' the CPS in discriminating survival. Even without any claim to superiority over the CPS, the ALBI score/grade has several advantages. Specifically, it does not require three of the five parameters involved in the CPS (including the two that are most subjective, ascites and encephalopathy), thereby making the classification more reliable between observers. A less obvious advantage is that it was built on an extensive evidence base, specifically for assessment of liver function in HCC and made no prior assumptions as to the presence or absence of cirrhosis. By contrast, the CPS is advocated for the assessment of liver function in patients with cirrhosis and, at least by convention, it should only be applied to such patients. This 
Table 4. Median survival according to each classification system in the various cohorts

\begin{tabular}{|c|c|c|c|c|c|}
\hline Cohort & Classification system & $N$ & $\begin{array}{l}\text { Median survival in months } \\
(95 \% \mathrm{Cl})\end{array}$ & Harrell's C & AIC \\
\hline \multicolumn{6}{|l|}{ Figure 1} \\
\hline Europe & $\begin{array}{l}\text { ALBI grade } 1 \\
\text { ALBI grade } 2 \\
\text { ALBI grade } 3\end{array}$ & $\begin{array}{c}384 \\
731 \\
82\end{array}$ & $\begin{array}{c}26.18(22.93,28.09) \\
14.61(13.39,15.92) \\
9.70(5.80,14.01)\end{array}$ & 0.5749 & 11269.51 \\
\hline Japan & $\begin{array}{l}\text { ALBI grade } 1 \\
\text { ALBI grade } 2 \\
\text { ALBI grade } 3\end{array}$ & $\begin{array}{c}85 \\
462 \\
106\end{array}$ & $\begin{array}{c}38.91(27.27,51.35) \\
22.43(19.61,25.39) \\
15.33(9.34,20.46)\end{array}$ & 0.566 & 5816.714 \\
\hline Hong Kong (China) & $\begin{array}{l}\text { ALBI grade } 1 \\
\text { ALBI grade } 2 \\
\text { ALBI grade } 3\end{array}$ & $\begin{array}{l}34 \\
98 \\
11\end{array}$ & $\begin{array}{c}30.20(16.84,47.17) \\
18.65(12.60,25.59) \\
6.05(1.22,14.18)\end{array}$ & 0.5898 & 995.5034 \\
\hline \multicolumn{6}{|l|}{ Figure 2} \\
\hline All & $\begin{array}{l}\text { C-P A } \\
\text { C-P B } \\
\text { C-P C }\end{array}$ & $\begin{array}{c}1791 \\
1055 \\
118\end{array}$ & $\begin{array}{c}21.78(20.00,23.65) \\
15.20(14.00,16.28) \\
8.26(5.00,12.40)\end{array}$ & 0.5586 & 26548.21 \\
\hline All & $\begin{array}{l}\text { HAP class A } \\
\text { HAP class B } \\
\text { HAP class C } \\
\text { HAP class D }\end{array}$ & $\begin{array}{l}349 \\
768 \\
955 \\
523\end{array}$ & $\begin{array}{c}32.96(28.00,37.57) \\
23.49(20.00,26.22) \\
18.00(16.81,19.14) \\
11.91(9.34,12.00)\end{array}$ & 0.6121 & 22273.51 \\
\hline All & $\begin{array}{l}\text { Without macrovascular invasion } \\
\text { With macrovascular invasion }\end{array}$ & $\begin{array}{c}2567 \\
447\end{array}$ & $\begin{array}{c}20.39(19.51,22.00) \\
8.22(7.34,9.87)\end{array}$ & $\begin{array}{l}\text { NA } \\
\text { NA }\end{array}$ & $\begin{array}{l}\text { NA } \\
\text { NA }\end{array}$ \\
\hline Japan & $\begin{array}{c}\text { VP0 } \\
\text { VP1 } \\
\text { VP2/3 } \\
\text { VP4 }\end{array}$ & $\begin{array}{c}450 \\
60 \\
110 \\
16\end{array}$ & $\begin{array}{c}28.19(25.82,31.11) \\
18.62(13.22,21.78) \\
9.54(7.43,11.58) \\
4.14(2.37,8.91)\end{array}$ & $\begin{array}{l}\text { NA } \\
\text { NA } \\
\text { NA } \\
\text { NA }\end{array}$ & $\begin{array}{l}\text { NA } \\
\text { NA } \\
\text { NA } \\
\text { NA }\end{array}$ \\
\hline
\end{tabular}

convention is generally not applied to patients with HCC being used widely, even with the knowledge that many patients with HBV-related HCC will not have cirrhosis. In our recent study, where we examined the extent of fibroses in resected HCC specimens and even among the Japanese patients, most of whom had HCV-related HCC, only $52 \%$ had cirrhosis (Toyoda et al, 2016a). It should not be assumed therefore that, because all patients with HCC were assigned a CPS by their local investigator, that all had cirrhosis.

The prevalence of VI (15\%) is in line with reports in the literature (Pirisi et al, 1998; Minagawa and Makuuchi, 2006; Yoshidome et al, 2011; Quirk et al, 2015; 10-40\%) and confirms that despite guidelines, suggesting that patients with VI should receive sorafenib, a significant proportion of those undergoing TACE did in fact have VI. The prognostic importance of VI is also seen in patients treated with curative intent (Toyoda et al, 2016b). Although the AASLD/ EASL guidelines (Llovet et al, 2008a) suggest the treatment with sorafenib rather than TACE for those with any degree of VI there is no explicit statement that suggests that VI is a contraindication to TACE and the data presented here suggest the extent of portal vein invasion is of major prognostic importance. Quirk et al (2015), have noted that overall survival after TACE in patients with VI ranges from 7.4 to 10.2 months in the literature (and in the series reported here), figures that are only marginally better than those obtained with systemic sorafenib (Llovet et al, 2008b).

\section{CONFLICT OF INTEREST}

The authors declare no conflict of interest.

\section{REFERENCES}

Adhoute X, Penaranda G, Castellani P, Perrier H, Bourliere M (2015) Recommendations for the use of chemoembolization in patients with hepatocellular carcinoma: Usefulness of scoring system? World J Hepatol 7: $521-531$.

Akaike H (1998) Selected Papers of Hirotugu Akaike. Springer.

Bruix J, Sherman M (2011) Management of hepatocellular carcinoma: an update. Hepatology 53: 1020-1022.

Chan AW, Chan RC, Wong GL, Wong VW, Choi PC, Chan HL, To KF (2015) New simple prognostic score for primary biliary cirrhosis: albumin-bilirubin score. J Gastroenterol Hepatol 30: 1391-1396.

Chan AW, Kumada T, Toyoda H, Tada T, Chong CC, Mo FK, Yeo W, Johnson PJ, Lai P, Chan AT (2016) Integration of albuminbilirubin (ALBI) score into Barcelona clinic liver cancer (BCLC) system for hepatocellular carcinoma. J Gastroenterol Hepatol 31: 1300-1306.

Curley SA, Stuart KE, Schwartz JM, Carithers R (2012) Nonsurgical Therapies for Localized Hepatocellular Carcinoma: Radiofrequency Ablation, Percutaneous Ethanol Injection, Thermal Ablation, and Cryoablation. Wolters Kluwer Health: Baltimore, MD, USA.

Forner A, Llovet JM, Bruix J (2012) Chemoembolization for intermediate HCC: is there proof of survival benefit? J Hepatol 56: 984-986.

Grieco A, Pompili M, Caminiti G, Miele L, Covino M, Alfei B, Rapaccini GL, Gasbarrini G (2005) Prognostic factors for survival in patients with early-intermediate hepatocellular carcinoma undergoing non-surgical therapy: comparison of Okuda, CLIP, and BCLC staging systems in a single Italian centre. Gut 54: 411-418.

Harrell Jr. FE, Califf RM, Pryor DB, Lee KL, Rosati RA (1982) Evaluating the yield of medical tests. JAMA 247: 2543-2546. 
Harrell Jr. FE, Lee KL, Mark DB (1996) Multivariable prognostic models: issues in developing models, evaluating assumptions and adequacy, and measuring and reducing errors. Stat Med 15: 361-387.

Hickey R, Mouli S, Kulik L, Desai K, Thornburg B, Ganger D, Baker T, Abecassis M, Ralph Kallini J, Gabr A, Gates VL, Benson III AB, Lewandowski RJ, Salem R (2016) Independent Analysis of albuminbilirubin grade in a 765-patient cohort treated with transarterial locoregional therapy for hepatocellular carcinoma. J Vasc Interv Radiol 27: 795-802.

Hiraoka A, Kumada T, Michitaka K, Toyoda H, Tada T, Ueki H, Kaneto M, Aibiki T, Okudaira T, Kawakami T (2015) Usefulness of albumin-bilirubin (ALBI) grade for evaluation of prognosis of 2584 Japanese patients with hepatocellular carcinoma. J Gastroenterol Hepatol 31: 1031-1036.

Hucke F, Pinter M, Graziadei I, Bota S, Vogel W, Müller C, Heinzl H, Waneck F, Trauner M, Peck-Radosavljevic M (2014) How to STATE suitability and START transarterial chemoembolization in patients with intermediate stage hepatocellular carcinoma. J Hepatol 61: 1287-1296.

Johnson PJ, Berhane S, Kagebayashi C, Satomura S, Teng M, Reeves HL, O’beirne J, Fox R, Skowronska A, Palmer D, Yeo W, Mo F, Lai P, Iparrairaegui M, Chan SL, Sangro B, Miksad R, Tada T, Kumada T, Toyoda H (2015) Assessment of liver function in patients with hepatocellular carcinoma: a new evidence-based approach-the ALBI grade. J Clin Oncol 33: 550-558.

Kadalayil L, Benini R, Pallan L, O’beirne J, Marelli L, Yu D, Hackshaw A, Fox R, Johnson P, Burroughs A (2013) A simple prognostic scoring system for patients receiving transarterial embolisation for hepatocellular cancer. Ann Oncol 24: 2565-2570.

Katagiri S, Yamamoto M (2014) Multidisciplinary treatments for hepatocellular carcinoma with major portal vein tumor thrombus. Surg Today 44: 219-226.

Kudo M, Kitano M, Sakurai T, Nishida N (2015) General Rules for the Clinical and Pathological Study of Primary Liver Cancer, Nationwide Follow-Up Survey and Clinical Practice Guidelines: The Outstanding Achievements of the Liver Cancer Study Group of Japan. Dig Dis 33: 765-770.

Lladó L, Virgili J, Figueras J, Valls C, Dominguez J, Rafecas A, Torras J, Fabregat J, Guardiola J, Jaurrieta E (2000) A prognostic index of the survival of patients with unresectable hepatocellular carcinoma after transcatheter arterial chemoembolization. Cancer 88: 50-57.

Llovet JM, Brú C, Bruix J (2008a) Prognosis of hepatocellular carcinoma: the BCLC staging classification. Semin Liver Dis 19: 329-338.

Llovet JM, Bruix J (2003) Systematic review of randomized trials for unresectable hepatocellular carcinoma: chemoembolization improves survival. Hepatology 37: 429-442.

Llovet JM, Real MI, Montaña X, Planas R, Coll S, Aponte J, Ayuso C, Sala M, Muchart J, Solà R (2002) Arterial embolisation or chemoembolisation versus symptomatic treatment in patients with unresectable hepatocellular carcinoma: a randomised controlled trial. Lancet 359: 1734-1739.

Llovet JM, Ricci S, Mazzaferro V, Hilgard P, Gane E, Blanc JF, De Oliveira AC, Santoro A, Raoul JL, Forner A, Schwartz M, Porta C, Zeuzem S, Bolondi L, Greten TF, Galle PR, Seitz JF, Borbath I, Haussinger D, Giannaris T, Shan M, Moscovici M, Voliotis D, Bruix J. Group, S. I. S. (2008b) Sorafenib in advanced hepatocellular carcinoma. N Engl J Med 359: 378-390.

Lo C-M, Ngan H, Tso W-K, Liu C-L, Lam C-M, Poon RT-P, Fan S-T, Wong J (2002) Randomized controlled trial of transarterial lipiodol chemoembolization for unresectable hepatocellular carcinoma. Hepatology 35: 1164-1171.

Marelli L, Stigliano R, Triantos C, Senzolo M, Cholongitas E, Davies N, Tibballs J, Meyer T, Patch DW, Burroughs AK (2007) Transarterial therapy for hepatocellular carcinoma: which technique is more effective? A systematic review of cohort and randomized studies. Cardiovasc Intervent Radiol 30: 6-25.
Meyer T, Kirkwood A, Roughton M, Beare S, Tsochatzis E, Yu D, Davies N, Williams E, Pereira S, Hochhauser D (2013) A randomised phase II/III trial of 3-weekly cisplatin-based sequential transarterial chemoembolisation vs embolisation alone for hepatocellular carcinoma. Br J Cancer 108: 1252-1259.

Minagawa M, Makuuchi M (2006) Treatment of hepatocellular carcinoma accompanied by portal vein tumor thrombus. World J Gastroenterol 12: 7561.

Newson RB (2010) Comparing the predictive powers of survival models using Harrell's C or Somers' D. Stata J 10: 339.

O'Suilleabhain C, Poon R, Yong J, Ooi G, Tso W, Fan S (2003) Factors predictive of 5-year survival after transarterial chemoembolization for inoperable hepatocellular carcinoma. Br J Surg 90: 325-331.

Oliveri RS, Wetterslev J, Gluud C. Transarterial (chemo) embolisation for unresectable hepatocellular carcinoma. Cochrane Database Syst Rev. 2011; (3): CD004787.

Pirisi M, Avellini C, Fabris C, Scott C, Bardus P, Soardo G, Beltrami CA, Bartoli E (1998) Portal vein thrombosis in hepatocellular carcinoma: age and sex distribution in an autopsy study. J Cancer Res Clin Oncol 124: 397-400.

Quirk M, Kim YH, Saab S, Lee EW (2015) Management of hepatocellular carcinoma with portal vein thrombosis. World J Gastroenterol 21: 3462.

Savastano S, Miotto D, Casarrubea G, Teso S, Chiesura-Corona M, Feltrin GP (1999) Transcatheter arterial chemoembolization for hepatocellular carcinoma in patients with Child's grade A or B cirrhosis: a multivariate analysis of prognostic factors. J Clin Gastroenterol 28: 334-340.

Takayasu K, Arii S, Ikai I, Omata M, Okita K, Ichida T, Matsuyama Y, Nakanuma Y, Kojiro M, Makuuchi M (2006) Prospective cohort study of transarterial chemoembolization for unresectable hepatocellular carcinoma in 8510 patients. Gastroenterology 131: 461-469.

Toyoda H, Kumada T, Osaki Y, Oka H, Urano F, Kudo M, Matsunaga T (2006) Staging hepatocellular carcinoma by a novel scoring system (BALAD score) based on serum markers. Clin Gastroenterol Hepatol 4: 1528-1536.

Toyoda H, Lai PB, O'beirne J, Chong CC, Berhane S, Reeves H, Manas D, Fox RP, Yeo W, Mo F, Chan AW, Tada T, Inarrairaegui M, Vogel A, Schweitzer N, Chan SL, Sangro B, Kumada T, Johnson PJ (2016a) Long-term impact of liver function on curative therapy for hepatocellular carcinoma: application of the ALBI grade. Br J Cancer 114: 744-750.

Toyoda H, Lai PB, O’beirne J, Chong CC, Berhane S, Reeves H, Manas D, Fox RP, Yeo W, Mo F, Chan AW, Tada T, Inarrairaegui M, Vogel A, Schweitzer N, Chan SL, Sangro B, Kumada T, Johnson PJ (2016b) Long-term impact of liver function on curative therapy for hepatocellular carcinoma: application of the ALBI grade. $\mathrm{Br} J$ Cancer 114: 744-750.

Yoshidome H, Takeuchi D, Kimura F, Shimizu H, Ohtsuka M, Kato A, Furukawa K, Yoshitomi H, Miyazaki M (2011) Treatment strategy for hepatocellular carcinoma with major portal vein or inferior vena cava invasion: a single institution experience. J Am Coll Surg 212: 796-803.

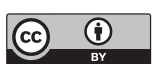

This work is licensed under the Creative Commons Attribution 4.0 International License. To view a copy of this license, visit http://creativecommons.org/licenses/by/4.0/

(C) The Author(s) named above 2017

Supplementary Information accompanies this paper on British Journal of Cancer website (http://www.nature.com/bjc) 